\title{
A Theoretical Evaluation of the Socio Economic Influence on the Employees of Bangladesh
}

\section{Md. Mosaddeak Khan Chowdhury}

Former Assistant Professor, Bangladesh University of Professionals (BUP), Dhaka, BANGLADESH

*Corresponding Contact:

Email: partho3057@gmail.com

\begin{abstract}
Human behavior in the sphere of life in general and in the area of job, in particular, depends on both internal and external factors. There are many well-accepted academic theories in regard to internal factors that affect job environment of the employees which eventually lead to their satisfaction or dissatisfaction. The external factors have not got such attention because these are country- specific and culture-specific phenomenon. Each country has its uniqueness which forms unique characteristic within her habitants. These country characteristics depend on various factors, and the fundamentals are those that are apparently beyond the immediate control of their people. History, topography, weather, socio-economic status of the people are few of the prominent factors that affect the job environment of most of the people of any particular country. In this paper, a theoretical evaluation of the effects of such prominent factors has been outlined keeping a farther scope to verify the postulates with real-time data.
\end{abstract}

Key Words: Topography, patron-client relationship, population and poverty, syndrome of affluence, historical influence, weather influence, fish justice

JEL Classification Code: A 14; J 08; Z 13

\section{INTRODUCTION}

Job satisfaction comprises of cognitive, affective and behavioral component of human behavior. Of these three, the cognitive component has earned focus in the theoretical perspective. The other two that is affective and behavioral components entail so many country specific and culture specific factors that make difficult to formulate any universal theory which will be applicable irrespective of country and culture. The determinants of all the intrinsic and extrinsic variables, judged at individual level, are found to be different across different countries. Some countries have more job satisfaction while others have less (taken all the individual considerations into account) (Wallace, 2008). This has been explained by taking the country-level institutional factors like unionization, inequality in average wage level, national employment rate etc. Comparative research also explains different value orientation through different cultures across the world (Vilert, 2003).Culture is a complex phenomenon which forms a total character of a human being. Theorizing about the 
relationship between cultural values and job satisfaction is a difficult task. In any organization people of different cultural values would oppose any management initiative if that doesn't manifest his cultural habit. It is clear that cultural values are subjective concept and it is difficult to quantify it (Baker, 2000). A safe estimation for determining the country level variables that affect individual in his job can be done by ascertaining the country characteristics. With that perspective in view, in order to put country premium in the cognitive and affective evaluation, it is imperative that local cultural characteristics of any country be evaluated before finding the variables that affect 'cognitive' and 'affective' components of human life. A natural argument is evoked as to what are the elements of the country that needs to be considered before bringing out any conclusion from it. There is no any short cut answer to it as much as there is no short cut way of finding the triggering aspects that form human psychology. An attempt will be made here to draw a generalization of overall country context like geography, weather, socio-political make up, economy etc. which have direct effect in forming the human character. Great writer Thomas Hardy through his epic novel 'Return of the Native' wanted to prove that each place - be it a country or a villagehas its own natural destiny and this fate is superimposed over the providence of the people living therein. Beyond the fictional postulates, by the standard of crude empirical evidence human fortune is so bound up with country characteristic that one is inseparable from the other. When the country is devastated by natural disaster, torn by war, struck by famine etc. the whole human mass become the unwilling victim of her misery. This influence of country is penetrated deep inside the human character and regulates their behavior in job, in family, in politics etc. In the working environment there is supposed to be some country differentials which has impact as to how someone would behave in his job irrespective of the job climate superimposed by the authority.

\section{ObJective OF THE Study}

The objectives of the study is to identify and evaluate various factors that influence in the job environment in the socio economic parameters of Bangladesh. Its' main purpose is to create a subsequent field for undertaking farther research in the area of socio-cultural influence in the job attitude of employees of Bangladesh in any particular sector.

\section{Methodology}

This is a theoretical evaluation only. No real data have been collected and tested within statistical parameter. The consideration is based on the secondary books and journals. The explanation of the various historical social inheritances is made by the empirical evidence perceived by the writer himself. This perceptual explanation may or may not hold good while doing data based experiment in any particular sector.

\section{HISTORICAL INFLUENCE}

The origin of Bangladeshi nationhood is about "psychological bond that joins people and differentiates it in the subconscious conviction of its members, from all other people in a most vital way" (Waker, 1978). A nation is more prominent by its psychological makeup which is a fabric of bondage within people. This framework of mind, though rooted in the history, is continuously nourished by some country originated independent variables. Among these some are extension of history and some has taken a hybrid shape with the advent of the concept of global society. The volatile root of BD has baffled the historians. An American political scientist has rightly observed "It is a country challenged by contradictions." According to one school "the emergence of Bangladesh is the culmination of divide and rule 
policy of the British Raj (Azad, 1975). Another school maintains that the evolution of Bangladesh is the reaction against economic deprivation (Rehman, 1992). All these postulates allude to the idea that BD people, owing to their environment, economy and demography had to be limited only with day to day gains and losses. This lack of internal ideological pursuits has built a type of character which is ever concern only with personal expeditionary gains. The absence of broader vision of life is rooted so much deep inside the character that day to day routine living of a person doesn't have any respect for rules of business in any spheres if the cost of rule breaking is less than the cost of rule followings. This created a judiciary culture of Matsanyam (fish eating fish) just after the demise of pal dynasty and its residual effect is still visible in present Bangladesh (Schendel, 2009). With this a de facto pervasive 'Matsanayam' or 'fish eating fish' sort of justice in the society the job environment is devoid of any rules of business to be followed but is infested with the notion of peoples' flocking under the custody of a local protector.

\section{TOPOGRAPHY}

Three forms of water- river rain and sea- give Bangladesh (BD) a natural janus face. Summer floods are a way of life. About 20percent of the country is inundated every summer due to rainfall. "Generally, the country is highly prone to natural hazards - a few of which take disastrous proportions. In most cases, however, disasters are manifested as hydrological events caused by climatic extremes (Khan, 1991)". "The country's geographical location, high dependence on the overall regional hydrology (Ganga Brahmaputra Meghna basin), spatial and temporal distribution of water resources - all contribute to the high degree of susceptibility of Bangladesh to water-related extreme events" (Ahmed, 2011). People live in a environment where land and water meet and where boundaries between these two elements are in constant flux. As a result the settlement patterns are always transient and always flexible- due to which Bangladeshi villages have been described as elusive (Bettrocci, 1996). This 'transientness' of collective lives and people's sole living on rice (a sedentary life style) have kept Bengali people rooted to the local civilizations where any attempt of juxtaposing global modern societal culture created an identity crisis with an perennial antagonism between this two. One of the social crisis stems from the aspiration of the educated people to delete the local stigma of village culture despite living with 'village culture' people all around them. This creates a gap between the aspiration and reality among the literate people. There are realities where things are dispensed basing on the judgment of local culture whereas learned people, in the process of being educated, expect to be treated with universal culture. It is more acceptable to verbally abuse/or even man handle a 'Rickshaw puller' for his any appropriate behavior than going for legal battle with him. Social ethics has not been originated from a common platform but from different source which are often in stark contrast with each other.

\section{WeAther}

Bangladesh has a hot, humid summer from April to October. The annual mean temperature is $36^{\circ} \mathrm{C}$ in most of the time of the year with this a high humidity makes the weather intolerable. Extreme heat or cold can have serious negative impacts. Importantly, what is 'normal' for one region may be extreme for another area that is less well adapted to such temperatures (Chris Huhne, 2011). Bangladesh ranks high in the list of most vulnerable countries on earth which is also recognized by the international community. Beyond the hydro-geological factors like its location, low elevated topography and climate variability there are also some socio economic reasons that have added to the vulnerability of climate change in Bangladesh . These 
are: (a) its high population density and poverty incidence; and (b) its majority of population being dependent on crop agriculture which is highly influenced by climate variability and change. Despite the recent strides towards achieving sustainable development, Bangladesh's potential to sustain its development is faced with significant challenges posed by climate change (Haque, 2002)

\section{Effect}

The people of Bangladesh remain under terrible GOD gifted pain due to the unbearable heat and humidity from weather. Somehow this weather trend couldn't be physiologically acclimatized by the mass people. The rich and the bosses can avoid the pain of such 'weather effect' by fixing air conditions in their houses, cars and office which exacerbate the temperature gradient and, consequently, turn the weather to be more painful for the greater unfortunate mass. Any body's higher ambition in this country includes, in the most part, to get rid of weather inflicted pain. There is no any government initiated 'all encompassing' policy, because of the country's poor economic status, where measures are adopted to keep everyone under cooling condition. It is the privilege given to a 'segmented few' according to their ranks and status. That means to be able to go in the higher ups in the social ladder is to be able to get rid of painful weather at the cost of increasing the pain of others. There is common empirical evidence that in hot and humidified intolerable weather the bosses of many institutions can afford to come with suited winter attire in the office where just in front of him his subordinates are profusely sweating due to heat and humidity. It bespeaks of a job environment where group of people in the same institution can afford to live in a 'shadow reality' of the country without understanding the actual weather that is affecting the others in a same institution. The sub-ordinates have accepted this to be a way of social or institutional life and it probably doesn't evoke any sense of insult in them. There have never been any social upheavals or revolution against these sarcastic acts of institutional bosses. In the context of 'perceived relative deprivation concept' to be able to remain in comfort just in the midst of 'pain inflicted' others gives a sense of superiority to the bosses by which they can maintain an air of authority over others. As for this variable i.e. weather, there is a subtle glimpse that the root of administrative system relies on some UN ethical platform which has evaded conscious evaluation of employers-employees, bosses-subordinates relations. Apart from the relational parameters in various professions, research shows about the enhancement of negative emotions during the period of adverse weather. Humidity with high temperatures has deepest effect on mood which also lowers the scores on concentration (Halfman, 1984). People affected by such adverse weather seem to have pathological attention deficit disorder which creates mutual intolerance and aggressive behavior within individuals. This attention deficit disorder keeps people very superficial and inflicts a shallow temporariness in their attitude.

\section{POPUlation AND POVERTY}

Over population in BD is not a new phenomenon. In fifteenth century it was one of the biggest cities in south Asia. In 1521 a Portuguese visitor found the roads were so thronged with traffic that it was difficult to move (Shendel, 2009). This legacy of overpopulation carried itself in the present when the size of people density reached 1,033 persons per square kilometre in 2015, three times the density of India and seven times China's. Bangladesh's exceptionally high population density makes it a "special case" among developing countries and is at risk of reaching saturation in terms of its ability to absorb further population growth (Streat Field, 2008). Although the population of Bangladesh has increased by 83 million persons since independence, the land under cultivation ("net cropped area") has declined by 6.6 percent. 
Essentially there is no "land frontier" remaining in Bangladesh that would allow the supply of land to be augmented. It has been estimated that 26,000 people per year are losing their land due to the effects of flooding and erosion (Hessel, 2013). The country and its citizenry are now exposed to a wide range of climate-related risks. Acute population pressure on the country's floodplains causes rural displacement and migration to urban areas.

\section{Effect}

Theory of affluence denotes as to be putting least value to those which they have got in plenty. In Bangladesh there is an oversupply of candidates in all the spheres where it concerns people. In any institution there is a long queue of aspirant employees for a single vacancy. It facilitates the employers to be over demanding from the employees and threatens the employees with constant fear of job in security. In more basic level the excessive population plays at the sub conscious level which engenders internal competition within people to have access to the limited resources. When there is public national wealth to share (for example, state-owned lands or mineral deposits), the birth of a new citizen dilutes everyone else's claim on this jointly owned property (Birdsall, 1994). This threat of personal insecurity posed by others promotes mutual intolerance within people. Apart from this the impact of overpopulation poses risks on environment and social hygiene. The environmental concern about rapid population growth is straightforward. For given levels of consumption, more people put more stress on natural resources, including both sources (forests, water) and sinks (the air which receives pollution). In the absence of prices that reflect the true scarcity value of these sources and sinks, there is likely to be excessive consumption of these "goods" from society's point of view.

\section{POVERTY}

The poverty in Bangladesh has got its historical roots. The medieval poet 'Vorot chondra' in his poem narrated a story where a boatman suddenly encounters a Goddess. Goddess wanted to grant him a wish and the boatman supplicated "amar shontan jano thake dhudhe vaate" a wish for the children so that they remain free from poverty. This reflects as the highest aspiration of common mass where anyone cannot ask anything more than food security even when he encounters GODDESS before him. There is a myth that Bengal had a golden economic age. The analysis of historical sources doesn't support this trend (khan, 1991). It had a fragile economic base which was highly vulnerable to the whims of nature. There were deep pockets of chronic poverty across the country and existence of slavery clearly indicates that destitution was wide spread (Khan, 2001). By the standard of GDP Bangladesh is one of the poorest countries in the world.

\section{Effect}

Poverty poses a 'poverty syndrome' where everybody remains in constant fear of resources insecurity. This becomes so inbuilt in character that tendency of insecurity never diminishes even when people is not within economic misery. Rapid population growth has negative "pecuniary" externalities, i.e., it reduces the incomes of the poor, compared to relatively affluent group, and therefore exacerbates the problems of poverty and income inequality in this country. This leads to perceived relative deprivation where the poverty is perceived to be magnified by seeing the affluence of others and at the same time the misery of the poor reminds a constant sense of insecurity in the minds of middle incoming group. 


\section{Patron Client Relationship Due to NEO Liberalism}

Politically Bangladesh can be considered as neo-patrimonial state where everything depends upon personal considerations, connections, favors, promises, and privileges' (Weber, 1978). Under this system, where the exchange of resources occurs between political officials and their associates, policies tend to be particularistic rather than universalistic in nature. The rule of law is secondary to the 'rule of man' and people in authority tend to blur the boundaries between the public and private realms (Eisenstadt, 1973). Patrimonialism promotes a culture where relationship between the executives and others fall into the patrimonial pattern of vassal and lord, rather than the 'rational-legal' and behavior is correspondingly calculated to reflect personal status, rather than to perform an official function (Clapham, 1985). The rural society in Bangladesh is highly fragmented and hierarchically structured based on minuscule distinctions in rank and status (M.M, 2013)

\section{Effects}

The above mentioned theoretical frame work denotes that the rule of law is very secondary in Bangladesh. Everything moves around personal connections which can be termed as social capital of specific nature. There is a syndicate of social association where the clients (Individuals who promise their allegiance for personal gains through patrons) manipulate his immediate material gains from patron and the latter in exchange demands service and respects from clients. Since there is no any ideological basis in it; users/clients immediately switch their loyalty from one patron to other judging on their relative strength. In the institutional levels many a time the employees of lower ranks sell their allegiance to political patrons who in exchange protect them from any professional hazards. Such relationship creates a culture of impunity to the employees for their infraction of institutional norms. This is more prominent in public institutions where the institutional performance doesn't directly affect the pay, promotion and benefits of the employees.

\section{CONCLUSION}

Only a few of the factors have been evaluated to show the country effect on human behavior that affects their jobs. As has been said; the 'well-being' and 'perception of satisfaction' in the life and in the job is a subjective concept which varies according to the personal disposition of an individual. People are pre disposed to different factors differently. There could be as many factors as there are a number of people. But there are some country-specific variables that define a mass behavior of the citizens. These can be considered as the 'truism' of the behavior of a general mass where little can be done to offset the pattern of country- specific psychology, but it surely would serve as an eye opener for anyone who deals with human behavior.

\section{REFERENCES}

Azad, M. R., Khan, W., \& Ahmed, A. A. A. (2011). HR Practices in Banking Sector on Perceived Employee Performance: A Case of Bangladesh. Eastern University Journal, 3(3), 30-39. https://doi.org/10.5281/zenodo.4043334

Ahmed, N., Nasima, M., \& Alam, N. (2013). Socio-Business Consideration of Garment Workers in Bangladesh: A Statistical Review. ABC Journal of Advanced Research, 2(2), 83-92. Retrieved from http://i-proclaim.my/archive/index.php/abcjar/article/view/175

Ahmed, S.M. (2011). Lives and Livelihoods on the street of Dhaka. Population board explanatory Survey.

Araya, A., Martorano, L., Girma, A., Habtu, S., Kebede, H., \& Hadgu, K. (2014). Comparative Efficiency Evaluation of Different Clay Pots Versus Bucket Irrigation System under Swiss Chard (Beta vulgaris subsp. 
cicla) Growers Condition in Northern Ethiopia. Malaysian Journal of Medical and Biological Research, 1(3), 125-

130. Retrieved from http://i-proclaim.my/archive/index.php/mjmbr/article/view/64

Azad, P. a. (1975). Politics and Soiety in Bengal. Middlesex: Penguin.

Baker, R. I. (2000). Modernization, cultural change and persistence of traditional values. American Sociological Review , 19-55.

Begum R, Ahmed AA and Neogy TK. 2012. Management Decisions and Univariate Analysis: Effects on Corporate Governance in Bangladesh Journal of Business Studies, 3, 87-115.

Bettrocci, P. (1996). Politics of community and culture of Bangladesh. Dhaka centre for social studies .

Birdsall, N. (1994). Government population and Poverty : a win win tale. Oxford: Transaction publishers.

Birdsall, N. (1994). Government Population and Poverty : A win-win tale. Brunwick, USA and Oxford UK: Transactio publishers.

Birdsall, N. (1999). Government population and poverty -a win win tale. Population and development , 2-3.

Chowdhury, M., Azam, M., \& Islam, S. (2015). Problems and Prospects of SME Financing in Bangladesh. Asian Business Review, 2(2), 51-58. doi: http:/ /dx.doi.org/10.18034/abr.v2i2.304

Chris huhne, M. (2011). Climat:observation, projection and Impact. Exter Devon: UK Met Office.

Clapham, C. (1985). Third world politics : an Introduction. Madison, Wisconsin: The university of Wisconsin press.

Eisenstadt, S. N. (1973). Traditional Patrimonialism and neo patrimonialism. California: Sage publication.

Faruk, M. (2015). The Effect of FDI to Accelerate the Economic Growth of Bangladesh and Some Problems \& Prospects of FDI. Asian Business Review, 2(2), 37-43. doi: http:/ /dx.doi.org/10.18034/abr.v2i2.302

Halfman, I. H. (1984). A multidimensiaon approach between Mood and Weather. Journal of Psychology .

Haque, A. A. (2002). Climat change and sustainable development. Dhaka: University Press .

Hessel. S. (2013). Living in a new land Char development in Bangladesh. Retrieved from http://ifadun.blogspot.co.nz/2013/02

Khan. A.A. (2001). Discovery of Bangladesh. Dhaka: The university Press limited.

Khan. F.H. (1991). Geology of Bangladesh. Dhaka: University Press Limited.

M.M, I. (2013). The toxic politics of bangladesh:A bipolar competitive neopatrimonial state. Asian Journal of Political science .

M.S, E. a. (1984). A multidimensional approach between mood and weather. NY: Journa of Psychology.

Neogy TK and Ahmed AA. 2015. The Extent of Disclosure of Different Components of Disclosure Index: A Study on Commercial Banks in Bangladesh Global Disclosure of Economics and Business, 2, 100-110.

Ogunyomi, O., Daisi, O., \& Oluwashikemi, R. (2013). Economic Globalization, Income Inequality and Economic Growth in Nigeria: A Static Data Analysis (1986-2010). ABC Journal of Advanced Research, 2(2), 130-143. Retrieved from http://i-proclaim.my/archive/index.php/abcjar/article/view/179

Rahman, M. (2013). Employees Motivation in Public and Private Commercial Banks in Bangladesh: A Study on Need-Based Approach. Global Disclosure of Economics and Business, 2(2), 151-158. Retrieved from http:/ /i-proclaim.my/archive/index.php/gdeb/article/view/144

Rehman, S. (1992). Economic basis of Bengali Nationalism. In S. Islam, History of Bangladesh. Dhaka: Asiatic Society of Bangladesh.

Sarker, S., Hasan, M., Das, S., \& Mazumder, S. (2014). Fish Culture Practice and Socio Economic Status in Northern Middle Part of Bangladesh. Malaysian Journal of Medical and Biological Research, 1(1), 4252. Retrieved from http://i-proclaim.my/archive/index.php/mjmbr/article/view/76

Schendel, W. V. (2009). A History of Bangladesh. New Delhi: Cambridge University Press.

Shendel, W. V. (2009). A History of Bangladesh. New Delhi: Cambridge University Press. 
Streat Field, P.K. (2008). Population Challenges of Bangladesh. Health Population and Nutrition .

Tasnim, Z., \& Hasnain, A. (2016). Identifying the Factors of a Happy Worker: Case of Private Banks of Bangladesh. Global Disclosure of Economics and Business, 5(1), 19-26. Retrieved from http://iproclaim.my/archive/index.php/gdeb/article/view/78

Ullah, M., \& Bhuiyan, F. (2013). Strategic Planning and Its Implications on SMEs in Bangladesh: An Empirical Study. Global Disclosure of Economics and Business, 2(1), 47-60. Retrieved from http://iproclaim.my/archive/index.php/gdeb/article/view/136

Vilert, H. X. (2003). Where intrinsic job satisfaction fails to work. Journal of organizational behavior , 159-179.

Waker, C. (1978). A nation is a nation-is a state is an ethnic group. Ethnic and Racial studies ,379-88.

Wallace, C. (2008, December 15). European Sociological Review. 535-549.

Wallace, F. P. (1978). A Nation is a nation-is a state-is an ethnic group in . Ethnic and Racial studies ,379-88.

Weber, M. (1978). Economy and Society: An outline of Interpretive Sociology. Berkley,CA: California Press.

$--0--$

Publish Online and Print Version Both

ISSN Online: 2307-9592 